Article

\title{
Factors Influencing Revenue Collection for Preventative Maintenance of Community Water Systems: A Fuzzy-Set Qualitative Comparative Analysis
}

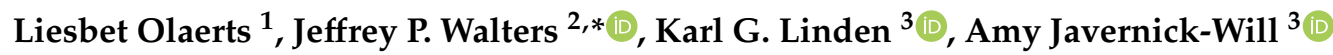 \\ and Adam Harvey ${ }^{4}$ \\ 1 Self Help Enterprises, Visalia, CA 93291, USA \\ 2 Department of Civil Engineering, College of Engineering, George Fox University, Newberg, OR 97132, USA \\ 3 Department of Civil, Environmental, and Architectural Engineering, University of Colorado Boulder, \\ Boulder, CO 80309, USA \\ 4 Whave, Kampala 72305, Uganda \\ * Correspondence: jwalters@georgefox.edu; Tel.: +1-971-412-8572
}

Received: 28 May 2019; Accepted: 4 July 2019; Published: 8 July 2019

\begin{abstract}
This study analyzed combinations of conditions that influence regular payments for water service in resource-limited communities. To do so, the study investigated 16 communities participating in a new preventive maintenance program in the Kamuli District of Uganda under a public-private partnership framework. First, this study identified conditions posited as important for collective payment compliance from a literature review. Then, drawing from data included in a water source report and by conducting semi-structured interviews with households and water user committees (WUC), we identified communities that were compliant with, or suspended from, preventative maintenance service payments. Through qualitative analyses of these data and case knowledge, we identified and characterized conditions that appeared to contribute to these outcomes. Then, we employed fuzzy-set qualitative comparative analysis (fsQCA) to determine the combinations of conditions that led to payment compliance. Overall, the findings from this study reveal distinct pathways of conditions that impact payment compliance and reflect the multifaceted nature of water point sustainability. Practically, the findings identify the processes needed for successful payment compliance, which include a strong WUC with proper support and training, user perceptions that the water quality is high and available in adequate quantities, ongoing support, and a lack of nearby water sources. A comprehensive understanding of the combined factors that lead to payment compliance can improve future preventative maintenance programs, guide the design of water service arrangements, and ultimately increase water service sustainability.
\end{abstract}

Keywords: sustainable water services; water payments; preventative maintenance; fuzzy-set qualitative comparative analysis

\section{Introduction}

Universal and reliable water service delivery is an important goal in sustainable development. However, the practical application of and methodologies for providing sustained water services in resource-limited communities vary greatly between regions and remains an enduring challenge for governments, communities, and institutions.

The UN declared the period between 1981 and 1990 as the Decade of Water. A consequence of this declaration was the widespread installation of water service infrastructure, particularly hand 
pumps, to increase water access in rural developing communities around the world. Since then, community-based management (CBM) of hand pumps has been the mainstay techno-institutional approach to rural water point development [1,2]. In CBM systems, water users are the key actors of water provision; communities have the responsibility and authority to financially manage, operate, and maintain their water facilities [3]. The CBM model has been promoted and promulgated broadly in rural areas across sub-Saharan Africa, mainly in response to the acknowledged failure of top-down, state-led approaches for water provision in these areas $[1,4,5]$. However, in the decades that followed, flaws in this techno-institutional coupling have also become apparent [6-9], with an estimated 10-65\% of hand pumps nonfunctional at any one time [10].

There have been numerous studies to understand what conditions are most influential for the sustainability of rural water supplies. These studies identified similar conditions that influenced the sustainability of rural water service delivery, despite differences in methodology and geographical context. In particular, revenue collection from water users has been shown to be a well-established cornerstone of a strong water system management scheme [2,3], and is widely regarded as critical to sustainability [1,11-17].

However, recent studies point toward the inability of water user committees (WUCs) to mobilize resources for the operations and maintenance (O\&M) of water systems. Specifically, a study by Carter et al. [18], which analyzed data from 92,594 water points fitted with hand pumps across five countries, found that three in five water points were not accompanied by any form of revenue collection, and only one in five water user groups regularly collected and saved funds in advance of a breakdown. Further, even where arrangements were put in place to regularly collect fees, a sizable proportion of water point users failed to meet their payment obligations [11,18].

As the challenges of CBM schemes become more apparent and documented (e.g., [19-21]), a preventive maintenance (PM) framework, which merges the professionalization and technical responsibilities of a public-private partnership (PPP) with performance-based contracts, has been viewed as a promising tool for achieving performance and financial sustainability of water services [22]. An active engagement of the private sector with governments, communities, and investors can potentially harness market incentives to improve service delivery, leverage institutional and governmental support to private capital for investment costs, and increase accountability of WUCs [22]. In addition, the importance of and decision-making for water user payment structures is a central part of financial sustainability, community management, and participatory planning; yet government engagement in payment formulation is generally less pronounced [20]. Policies are commonly agnostic about the revenue collection approach, and the ones that venture into the realm of rural water user tariffs find little consensus about preferred payment models [23].

While there is an established body of literature examining conditions that effect water user payments under a CBM framework, there is a dearth of literature that evaluates if the same conditions, or combination of conditions, also play a role in a PPP-based PM service models. This point is particularly important considering the growing body of literature supporting the adoption of systems approaches to water interventions, whereby the interconnected relationships between conditions are understood and considered in the planning, development, and management of water services [24-27]. Thus, this research aims to build on prior work by empirically assessing the conditions that contribute to successful user fee collection under a new PPP program, whereby PM services are provided to rural communities in the Kamuli District of Uganda. We then integrate the key conditions into a multifaceted approach that recognizes and evaluates their intrinsic interrelatedness by employing fuzzy-set Qualitative Comparative Analysis (fsQCA).

\section{Materials and Methods}

In this study, we use an integrated approach to investigate the conditions present within communities that motivate or hinder successful payment compliance. We recognize that these conditions rarely operate in isolation, and instead affect, and are affected by, one another; therefore, 
we employ qualitative comparative analysis (QCA) to better understand the multifaceted pathways that lead to success or failure in collective payment. For this paper in particular, successful collective payment is when a community pays the required annual fee in exchange for PM services and is 'compliant' with their PM service agreement.

Recently, QCA has seen increasing application within the international water and sanitation sector research to reveal and characterize the complex drivers of water and sanitation service delivery outcomes, including water and sanitation in schools [28,29], water points [9], sanitation infrastructure [30], and overall service sustainability [31-33]. QCA is particularly useful for describing complex causal relationships by analyzing the ways in which conditions combine together to yield an outcome, rather than quantifying the effects of independent variables [34-36]. QCA retains the power of rich, in-depth knowledge of cases, while providing more generalizable results from the analysis [37]. QCA is particularly well suited to intermediate sample sizes that fall between the small sample size of traditional case studies and the large sample size of statistical analyses [37]. Issues of validity are addressed through strong case orientation [38]. Cases are purposively selected to allow for modest generalization, or external validity, and in-depth case knowledge helps ensure internal validity, both in selecting conditions, assigning values for cases, and in interpreting the results [39]. Through qualitative and quantitative data, QCA identifies causal pathways of conditions that lead to a specific outcome of interest [38]. Conditions are factors identified from theory or case knowledge that are hypothesized to influence an outcome of interest, whereas pathways are the combinations of causal conditions that together lead to an outcome of interest.

Within this study, we used fuzzy-set qualitative comparative analysis (fsQCA). fsQCA can be used when finer gradations in the dataset are present and significant, where each variable is assigned a value along a range between 0 and 1 . Because of the nuanced nature of the conditions influencing payment compliance, fsQCA was selected over other forms of QCA that focus on categorical variables (crisp-set and multi-value QCA) [40,41]. Figure 1 illustrates the fsQCA process used in this study to assess the conditions and causal pathways for successful community payment compliance. This process is based on steps described by Kaminsky and Jordan [42] for the application of QCA for water, sanitation and hygiene (WASH) research as illustrated in Figure 1. Although shown in a linear progression, employing fsQCA is an iterative process informed by a thoughtful interpretation of model outputs. We discuss the fsQCA process below in more detail.

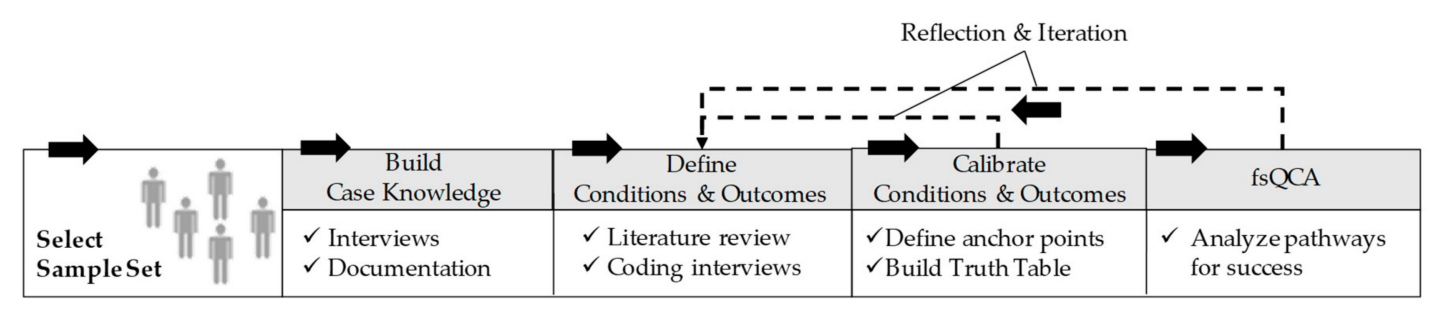

Figure 1. Research process overview (modified from Kaminsky and Jordan [42]).

\subsection{Study Context and Sample Set}

Uganda has an estimated population of 37.8 million, of which $85 \%$ resides in rural areas [43]. Poverty remains firmly entrenched in rural areas, where remote rural communities and smallholder farmers face significant challenges for sustainable water supply. A study assessing the effectiveness of CBM rural water supply facilities reported that only $53 \%$ of the sources were found to be fully functional [13]. The rest of the facilities were either broken down or abandoned, while others only provided water intermittently [13].

Our study analyzed a new PM program in the Kamuli District of Uganda run by a Ugandan nonprofit social enterprise, Whave, hereafter called 'PM service provider.' The PM program was implemented in five districts in Uganda. As part of the PM program, the PM service provider currently conducts regular water analyses to monitor water quality and provides PM year-round to ensure 
functionality of water sources. In most cases, the service provider, with support from communities and external partners such as nongovernmental organizations (NGOs) or local governments, rehabilitates the water source as a first step in signing up a PM service agreement. Subsequently, all minor and major parts replacements are covered by the service agreement and service fee. In cases where the water issues are extreme, or the action required falls beyond the service provider's service scope (i.e., silting of the borehole, construction of a new water source), the community receives guidance on alternative options such as where and how to obtain necessary funding.

At the time of our study, local entrepreneurs would collect WUC fee payments every six months to a year and would not be involved with the collection of household payments. As stated in the PPP contract, the WUC was responsible for water payment collection at the household (water user) level. Lacking a more formal guidance or framework, payment modalities of households varied greatly from community to community. Payment modalities of households, including frequency and price, were defined by each WUC. In most cases, WUC would start by collecting household payments on a monthly basis. As the WUCs participating in the study began experiencing challenges in collecting household payments, the frequency and price of payments tended to change with time. To address these challenges, communities would try different strategies, such as lowering the household fee, locking the pump, and changing payment collection times to quarterly, after the harvest period, or during the dry season.

Because the financial viability of the model is largely based on water user tariffs, community engagement in service agreements (i.e., the community is willing to sign a PM agreement, attend and participate in meetings, and be involved with activities related to PM service) is a key component to improve financial sustainability and scale the model. This is especially important considering that, of 120 contracts signed in the Kamuli District in 2017, 20.8\% are currently suspended and $10 \%$ are on warning of suspension due to payment noncompliance [44].

To optimize the potential for fsQCA analyses to produce meaningful insights regarding the drivers of payment compliance, study cases (communities) were selected based on variability between payment compliance outcomes and associated causal conditions. [34,39]. To guide the selection of the communities, we evaluated data provided by the water source baseline assessment conducted by the PM service provider [44].

The primary criteria for case selection was compliance with the PM service agreement. A community was considered 'compliant' when they paid an annual fee in exchange for PM service, and 'suspended' when they failed to pay for services. Sixteen community cases were selected; eight were compliant, and eight were suspended. Each selected community had one hand pump facility and varied in terms of number of households being served by the water point, hand pump depth, and an external implementing organization. Community cases were selected from rural areas of two sub-counties in the Kamuli District of Uganda representing different compliance rates: Bulopa and Wankole. In both sub-counties, between 31 and $42 \%$ of the hand pumps were under a preventive maintenance service agreement (PMSA) with the PM service provider. Bulopa had an overall high compliance rate ( $80 \%$ of the PMSAs are compliant), whereas Wankole, one of the PM service provider's first sub-counties in Kamuli, had about half that compliance rate (only $44 \%$ of the PMSAs signed are still compliant).

Each selected community had one hand pump facility and varied in terms of number of households being served by the water point, hand pump depth, and implementing organizations. All communities were difficult to access and lacked access to basic infrastructure such as roads, vehicles, and adequate sanitation. Most families in these communities live below the poverty line on subsistence agriculture, with some families building bricks to sell in nearby bigger communities. Illiteracy is high and most families do not have proper housing facilities and lack access to health care and other social services. 


\subsection{Conditions and Outcomes}

An initial list of conditions impacting payment compliance was created from the literature (see Supplementary Table S1, for the definitions of conditions and citations). For example, the literature showed (e.g., [45]; Terry et al. [46]) that the lack of training programs (condition WUC Ongoing Training and Support) can result in poor management and disorganized WUC, which in turn would lead to water users' mistrust and reduced willingness to contribute with water payments. Another condition identified was Alternative Improved Water Sources, whereby the literature showed that existence of alternative water sources reduces community members' willingness to pay for water from protected sources [12,17,47-49]. These conditions, and the other listed in Table S1, were used to develop the interview questions.

\subsection{Data Collection}

Data were collected to characterize each condition and system outcomes in each of the sixteen cases through interviews, documentation, and observations. Interviews were conducted with water users, and WUC members and ranged in duration from 45 minutes to one hour. Interviews had a mix of closeand open-ended questions adapted for water users and WUC members. Interview questions were guided by conditions identified in the literature and worded to explore deeper context-specific aspects of these conditions. For example, one question asked "Did the WUC have access to any type of training (condition WUC Training and Support)?" and then asked open-ended follow-up questions to describe nuanced elements of each condition such as, "If yes, what type of training?". The interview scripts can be found in Table S2. Interviews were collected with a local translator. A total of 40 interviews were conducted; 18 interviews with WUC members and 22 interviews with households.

Available documentation was collected in order to triangulate data from interviews. One such document was a water source baseline assessment report developed by the PM service provider in 2017 [44]. The baseline water source report yielded important information such as water source performance, functionality, and maintenance status. We also took field observations in each community to evaluate the water source condition, functionality, performance, and cleanness of the surrounding area, which could reflect proper use or misuse. For example, to evaluate if the WUC was taking responsibility of the water source, we assessed the general condition of the water source, the drainage channel, and the surrounding area. The general functionality and performance of the water source was also assessed by evaluating the condition of the pump handle and conducting a simple stroke and leakage test [1].

All data collection procedures were in accordance with our IRB-approved protocol (University of Colorado Boulder IRB \#18-0063).

\subsection{Analysis of Conditions and Outcomes}

To process information on conditions, the data gathered, including interview data, documentation, and field notes, were imported into QSR NVivo [50] and coded. Coding is a process where qualitative data is categorized based on important themes of interest, called codes [51]. Qualitative data were coded using deductive and inductive methods [52]. Deductive coding was based upon the conditions identified from the literature review, whereas inductive coding allowed nuanced themes to emerge from the data. In this study, we had one condition emerge: previous breakdowns and funds misusage experience (BreakDown). From our interviews, we found that a prior negative experience with breakdown may lead community members to be more willing to pay for PM services.

We eliminated four conditions in our study. Due to the need for variation in our collected data, we eliminated two conditions that did not vary, called domain conditions in QCA. For example, a greater representation of women in WUC was hypothesized to be a major influence on payment compliance. However, because this condition did not vary across our cases, the condition 'women representation in WUC' was not included in the fsQCA. Similarly, 'reliable maintenance service' was 
a domain condition not included in the study. We eliminated two other conditions-rainfall pattern and productive water use-as there was a lack of information to assess differences between cases.

Lastly, as it is common practice in an intermediate $\mathrm{N}$ analysis (between 10 and 40 cases) to select from four to seven conditions [53], we further distilled down the list to only include six conditions in the fsQCA. To do this, we affinity-grouped conditions that were correlated or could be combined. For example, the condition WUC organization (WUCorg) aggregated three main organizational aspects of WUC observed on the ground: degree of responsibility, existence of conflicts, and degree of legitimacy of WUC, which analyzed whether the WUC had a constitution, was legally registered at the sub-county government, and had a bank account. Table S1 shows how initial conditions were aggregated.

Thus, the six conditions included in the fsQCA were: previous experience with breakdown and funds misusage (BreakDown); alternative improved water sources (AltSource); water quality and availability perception (WatAvailEQual); WUC organization (WUCorg); ongoing support and communication (Supp\&Com); and, perception about water payment (PayPerception). These conditions are also reflective of the findings from a number of key studies that analyzed factors influential to collective payment $[1,12,17,20,47]$ and are cited as being significant in water user payment compliance. Table 1 shows the selected list of conditions that were analyzed for association with payment compliance in fsQCA with their respective definition and source.

Table 1. Hypothesized causal conditions that influence payment compliance used for QCA.

\begin{tabular}{|c|c|c|}
\hline $\begin{array}{l}\text { Hypothesized Causal } \\
\text { Condition }\end{array}$ & Definition & Citation/Source \\
\hline $\begin{array}{c}\text { Water Availability and Quality } \\
\text { perception } \\
\text { (WatAvailEQual) }\end{array}$ & $\begin{array}{l}\text { Community members experience } \\
\text { reliable water supply and perceived } \\
\text { their water of good quality. }\end{array}$ & $\begin{array}{l}\text { Foster and Hope (2016) } \\
\text { Kativhu et al. (2017) }\end{array}$ \\
\hline $\begin{array}{c}\text { Alternative Improved Water } \\
\text { Sources } \\
(\text { AltSources })\end{array}$ & $\begin{array}{l}\text { Community members have access to } \\
\text { other nearby improved sources that } \\
\text { are functioning, cheaper, or for free. }\end{array}$ & $\begin{array}{l}\text { Broek and Brown (2015) } \\
\text { Koehler et al. (2015) } \\
\text { Foster and Hope (2016) } \\
\text { Whittington et al. (2009) }\end{array}$ \\
\hline $\begin{array}{l}\text { Previous breakdowns and } \\
\text { funds misusage experience } \\
\text { (Breakdown) }\end{array}$ & $\begin{array}{l}\text { A community's prior exposure to } \\
\text { breakdowns of hand pumps and } \\
\text { misusage of funds and the impact on } \\
\text { community trust. }\end{array}$ & Case Knowledge \\
\hline $\begin{array}{l}\text { WUC Organization } \\
\text { (WUCorg) }\end{array}$ & $\begin{array}{l}\text { WUC takes active responsibility for } \\
\text { water source with no significant WUC } \\
\text { conflict; WUC has legal status and } \\
\text { authority to perform their task. }\end{array}$ & $\begin{array}{l}\text { Broek and Brown (2015) } \\
\text { Harvey et al. (2006) } \\
\text { Kamruzzaman et al. (2013) } \\
\text { Madrigal et al. (2011) } \\
\text { Kwangare et al. (2014) }\end{array}$ \\
\hline $\begin{array}{l}\text { Ongoing Support \& } \\
\text { Communication } \\
\text { (SuppEComm) }\end{array}$ & $\begin{array}{l}\text { There is an overall understanding } \\
\text { about the PM model with no } \\
\text { significant miscommunication. WUC } \\
\text { members feel that they have technical } \\
\text { and managerial support for ongoing } \\
\text { O\&M. }\end{array}$ & $\begin{array}{l}\text { Quin et al. (2011) } \\
\text { Terry et al. (2015) } \\
\text { Case knowledge }\end{array}$ \\
\hline $\begin{array}{l}\text { Perception about Water } \\
\text { Payments } \\
\text { (PayPerception) }\end{array}$ & $\begin{array}{l}\text { The general belief among people that } \\
\text { water should be free of charge, and/or } \\
\text { expectation that payments should be } \\
\text { collected only when the hand pump is } \\
\text { broken. }\end{array}$ & $\begin{array}{l}\text { Broek and Brown (2015) } \\
\text { Foster and Hope (2017) } \\
\text { Whittington et al. (2009) }\end{array}$ \\
\hline
\end{tabular}

Lastly, the outcome condition-Successful Payment Compliance—was identified using an aggregated score of payment compliance status, community struggle to achieve compliance, and WUC member's knowledge about their status. In particular, a fuzzy-set score was developed to reflect four distinct service outcomes observed in the field: (i) the PM agreement was suspended, that is, the community 
was noncompliant with payments (0: fully outside the set); (ii) the PM agreement was suspended, however, WUC members are not aware of the suspension (0.33: partially outside the set); (iii) the PM agreement was compliant, however, the community was struggling to be compliant with payments (0.66: partially in the set); and lastly, (iv) the PM agreement was compliant and the community wanted to sign the service agreement again (1: fully in the set). Evaluation of WUC awareness of suspension was based on Question 41 from the interview script (Table S2, Q41: "why the agreement is on warning/suspend?"), whereby the interviewee's indication of compliance in the event that services had been suspended signaled a lack of awareness. Evaluation of compliance struggles was evaluated through discussion with the PM service provider regarding challenges faced by communities to achieve payment compliance.

\subsection{Condition Calibration}

Based upon the data collected and our case knowledge, we calibrated conditions and outcomes as values between 0 , fully out of the set, to 1 , fully in the set. Calibration scores and definitions, similar to rubrics, are created for validity when performing cross-comparisons. Intermediate scores between 0 and 1 were determined qualitatively based on a set membership approach and "anchor points." Anchor points represent partial-set membership (whether in or out) cutoff points derived from theoretical and case knowledge to reflect meaningful separations between cases. These distinctions often resulted in fuzzy-set scores of: 0 (fully outside the set), 0.33 (partially outside the set), 0.67 (partially in the set), or 1 (fully in the set).

Table 2 shows an example for WUCorg calibration table. Table S3 shows the calibration scores and definitions for each condition and outcome.

Table 2. Calibration for WUC Organization.

\begin{tabular}{cl}
\hline Fuzzy-Score & \multicolumn{1}{c}{ Definition } \\
\hline 0 & Out-of-set. No active WUC. \\
\hline 0.33 & $\begin{array}{l}\text { Partially out-of-set. WUC takes minimal responsibility with occasional } \\
\text { lapses in management or is unorganized, has intra-WUC conflicts, } \\
\text { and WUC members provide contradictory information. }\end{array}$ \\
\hline \multirow{2}{*}{0.67} & $\begin{array}{l}\text { Partially in-set. WUC takes responsibility for water source with no } \\
\text { significant WUC conflict, WUC has a constitution, and collects } \\
\text { payments records but is not legally registered nor has a bank account }\end{array}$ \\
\hline & $\begin{array}{l}\text { In-set. WUC takes active responsibility for water source with no } \\
\text { significant WUC conflict, is legally registered, has a bank account, } \\
\text { and collects payments records. }\end{array}$ \\
\hline
\end{tabular}

Each condition, as well as the outcome, was calibrated using a similar process. Fuzzy scores for all conditions and outcomes were then assigned for every case and summarized in a truth table. The truth table, listing scores for each condition and outcome by case, is shown in Table S4.

\subsection{Data Analysis with $f_{s} Q C A$}

The fsQCA software [54] was used to analyze the truth table and identify pathways to successful payment compliance. We employed the intermediate solution set, as it permitted the integration of counterfactuals and case knowledge to simplify and strengthen the assumptions about whether the presence or absence of conditions would lead to case outcomes [42]. We assumed that the presence of conditions would influence compliance (success) and the absence of conditions would influence noncompliance (failure). Exceptions included AltSources and PayPerception, where the presence of these conditions were hypothesized to influence failure and the absence were hypothesized to influence success. 
The solution pathways leading to payment compliance were evaluated for level of significance using consistency and coverage metrics. Consistency measures the degree (between 0 and 1 ) to which cases sharing the same causal pathway solution have the same outcome; in our case, how consistently a pathway leads to payment compliance. Coverage, on the other hand, is the percent of cases (between 0 and 1) with an outcome that are explained by a given pathway. For the purposes of this research, significance of a pathway solution was based on a consistency value of 0.8 , which is a best practice for fsQCA analysis [53].

Another commonly used metric is to examine the "necessity" (also measured between 0 and 1 ) of individual conditions in leading to each outcome of interest. The calculation for necessity is shown in Equation (1), where $\mathrm{X} i$ is the membership score for a given combination of conditions and $\mathrm{Yi}_{i}$ is the outcome score for that combination [55]. A condition is necessary when all (or nearly all) instances of the outcome show the condition. Necessity scores above 0.9 are generally required for a condition to be considered necessary [34].

$$
\text { Necessity }=\frac{\sum \min \left(X_{i} Y_{i}\right)}{\sum Y_{i}}
$$

\section{Results and Discussion}

This section discusses the study findings evaluating the 16 cases using coding strategies and fsQCA. First, the condition pathways that lead to PM service compliance in Kamuli obtained through fsQCA are examined. Second, we discuss the key implications for implementing PM schemes within the larger water sector.

\subsection{Pathways to Payment Compliance}

We found three pathways to success, shown in Figure 2, which had a solution set consistency of 0.952 and coverage of 0.835 . These results present three compelling observations: 1) WUCorg and WatAvailQual appear in all the pathways; 2) two conditions (BreakDown and AltSources) appear to influence user's payment perception (PayPerception); and, 3) BreakDown and the lack of AltSources appear to have a 'neutralizing' effect, where the existence of one negates influence of the other on payment compliance. These observations are described below.

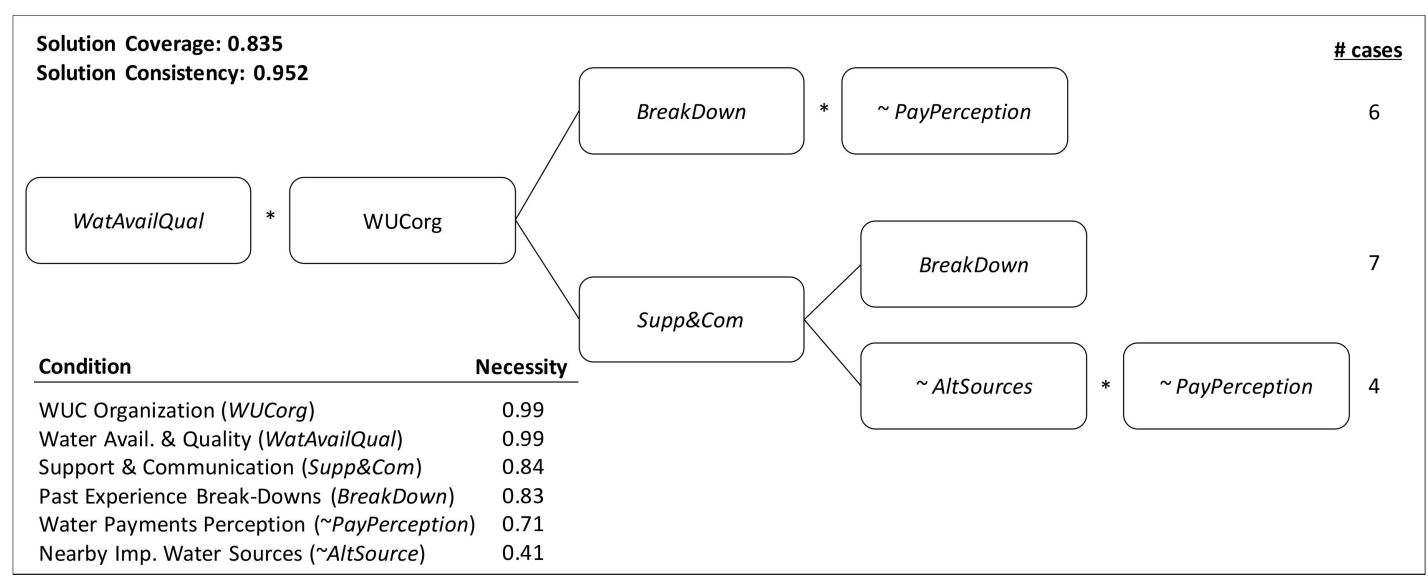

Figure 2. Pathways to successful payment compliance. Note: '*' means 'and,' ' ${ }^{\prime}$ means 'absent,' and lines represent distinctions between separate pathways.

\subsection{Observation 1: WUCorg \& WatAvailQual are Critical for Payment Compliance}

Our findings suggest that, for a community to be compliant with payments, it is necessary that users perceive that their water is of good quality and available in adequate quantities (WatAvailQual), while having a well-organized and active WUC (WUCorg). These two conditions appeared in all 
pathways and the necessity scores for each was higher than 0.9 , which is the criteria for a condition to be considered necessary [34].

While some failed cases could also have adequate available water and offer perceived good quality, the condition (WatAvail\&Qual) appears necessary for successful cases. Six out of eight noncompliant cases had issues with WatAvailQual, forcing water users to search for alternative sources. As one WUC member mentioned, "After pumping a lot the water reduces, especially during the dry seasons. When that happens, we wait until the water comes back or go to the open pond." Conversely, a WUC member from a compliant case points to WatAvailQual as an important driver of community satisfaction with the water service:

“... completely satisfied with the services because before (the PM service provider's program) the hand pump was in bad conditions, breaking all the time, and the water would change color. Now the hand pump is working well and (the PM service provider) helped to rehabilitate the hand pump and solve the water color issue."

Similarly, the WUC's role and ability to organize (WUCorg) was necessary for payment compliance under the PM model. We verified that, in the same way that poor WUC organization can negatively impact payment compliance, a well-organized WUC can absolve many otherwise confounding issues in a community. For example, although collecting water payments was an important challenge for all cases, a well-organized WUC could conceivably address these barriers with the resources they have or provide a feasible plan to overcome them. An interesting comment from a water user reflects the positive experience users have with a well-structured and organized WUC:

"The WUC mobilize the community for meetings and hygiene issues. We can follow where the money goes, so that gives us trust. Because WUC do meetings to report on the money issues, people talk about that and we trust what people are saying."

More compelling is the apparent interconnectivity between multiple conditions, namely WatAvailEQual, WUCorg, and the conditions SuppECom and PayPerception, found in different pathways of the fsQCA model. Our findings clearly show that successful compliance cases had the presence of perceived quality, reliable and plentiful water service provision (WatAvail\&Qual), and a well-organized WUC (WUCorg). Progressing further down the pathways offers more nuanced insights. Four out of five cases with low scores for WUCorg also received low scores for SuppECom (community understanding and communication related to PM models) and PayPerception (user opinion that water should be free). These four cases received a low score for these two conditions due to the existence of: (i) significant intra-WUC conflicts; (ii) critical miscommunication between WUC, water users, and service provider; and, (iii) a widespread belief among users that water should be free of charge or the expectation that payments should be collected only when the hand pump is broken (PayPerception). In one case, a community had a pump that had been broken for weeks due to misuse and disrepair, with no action made to resolve the issue. A WUC member in this community commented:

"... Our main problem is that the WUC is not united, mostly because the WUC chairperson is not cooperative. He wanted to give water for free and not collect water fees. I am trying to collect water fees, but is difficult because as there are some conflicts, people don't want to pay anymore."

We posit from these findings that the lack of a well-organized WUC (WUCorg) leads to miscommunication and lack of understanding among users about how their water source is managed (Supp\&Com). The conflicts and misunderstandings further resulted in mistrust and low willingness to pay for water, reinforcing the general belief among users that water should be free of charge or that revenues should be collected only when the source is broken (PayPerception). Indeed, water users mistrusting WUCs due to fear of mismanagement of funds is a well-documented condition within literature $[1,22,56]$.

Overall, these results align with previous studies correlating water quality and users' willingness to pay for water $[47,49,57]$, and studies assessing CBM performance that make reference to the importance of an active and well-organized WUC to promote service sustainability $[1,17,57]$. Our findings highlight the importance of these same user committees for PM model success under a PPP framework. They also elucidate and operationalize interlinkages between WUCorg, Supp\&Com, and PayPerception, 
reinforcing the need to build capacity among WUC around subjects such as payment perception, communication strategies, and conflict resolution skills. This is especially important considering that the condition Supp\&Com was present in two of the three pathways for payment compliance, with a consistency score of 0.835 .

\subsection{Observation 2: BreakDown and AltSources Appear to Influence PayPerception}

The two pathways that share PayPerception are preceded by two conditions that appear to contribute to water users' positive perception of payment, namely: (i) the presence of BreakDown, a community's prior exposure to continuous breakdowns and misusage of funds; and, (ii) the absence of AltSources, cases in which community members lack alternative improved water sources. Within our cases, both conditions (presence of BreakDown and absence of AltSources) contribute to water users' understanding of the benefits of regular payments for $\mathrm{PM}$, where users value a continued functionality of their improved water sources and a water service structure with more accountability and transparency. A comment from a water user reflects the change experience by the community with a well-established PM service: "There is a big difference. Before [the PM program] the hand pump was in bad condition, breaking all the time, and the water would change color. Now the hand pump is working well and [the PM program] helped to rehabilitate the hand pump." A quote from another water user points to the importance of a well-functioning water service being the primary water source: ". . because our hand pump is our only source of water, it is not difficult for the WUC to take care of the hand pump and it is very important for us to fix any problem very fast."

The first pathway WatAvail\&Qual * WUCorg * BreakDown * PayPerception reflects how the PM framework is contributing to users' understanding of regular payments. The ' $\sim$ ' indicates an absence of belief that water services should be free or that fees need only be collected when a breakdown occurs. By providing water source reliability and encouraging WUCs to obtain legal status so that they are responsible for formal and supervised banking of tariff revenues, users overcome mistrust from past experiences of funds misusage and poor O\&M of their water sources. This, in turn, is reflected in their payment perception and their willingness to regularly contribute to water revenues. This finding aligns with our case knowledge as well as the study by Koehler et al. [48] that indicates that payment structures are more likely to be accepted if service maintenance is provided reliably S [49]. This implies that a lack of alternative water sources may result in users who value and are more willing to pay to properly maintain their water systems, and thus, better understand the importance of regular payments.

These results align with literature that references the consequences of clustering hand pumps in a small region as it reduces incentives for payment [49]. The existence of nearby improved water sources poses a significant challenge to collect water revenues, especially when that access is for free. We infer that the access to 'free' water reinforces the general belief from nearby users that water should be free of charge or that payments should be collected only when the hand pump needs to be repaired. Consequently, users have a negative perception of user fees (PayPerception) and thus fail to regularly contribute with payments for PM services.

\subsection{Observation 3: 'Neutralizing' Effect of BreakDown on Lack of AltSources}

In addition to having water perceived to have adequate availability and perceived good quality (WatAvail\&Qual) and the WUC's role and ability to organize (WUCorg), pathways for successful payment compliance either had prior experience with breakdowns (BreakDown) or a lack of alternative sources (AltSources). The presence of BreakDown and absence of AltSources within the three pathways results in users that value and are more willing to properly maintain their water system, and thus, better appreciate the importance of regular payments. Interestingly, our findings indicate that users with previous negative experience of breakdowns and mistrust will continue to value and appreciate the importance of regular payments even when having access to alternative water sources. In other words, depending on their previous experiences with O\&M of water sources, users' value reliable 
and timely maintenance service over nearby improved water sources with intermittent functionality, as a WUC member commented:

“... while our hand pump does not break, a nearby hand pump that is not under a PM agreement breaks all the time. Some members of that community even joined our hand pump and started to pay because our hand pump is functioning all the time."

While it is difficult to assess the degree of influence between each condition and outcome within an fsQCA solution, quotes such as these from water users and WUC members perhaps suggest that BreakDown plays a stronger role, both directly (consistency score of 0.83 ) and indirectly, than AltSources on payment compliance.

\subsection{Limitations and Future Work}

The analysis and interpretations in this study come with several qualifications and limitations, including the relatively small sample size of 16 nonrandomly selected cases, which limits the generalizability of findings. First, the main limitation of this work is the reliance on member interviews, which offer subjective perspectives. As the accuracy of fsQCA is largely dependent on the quality of the information obtained through the translation of the interview responses, the possibility of undetected translation errors or omitted information cannot be ruled out. However, this limitation is reduced by triangulating our observations and document analysis with our interpretation of the findings.

Second, even though fsQCA is an established methodology that quantifies and organizes intimate case knowledge to more generalizable findings by identifying pathways of causal conditions to a determined outcome, no relationships can be conclusively demonstrated between variables. For example, the study was not able to better understand the relationship and degree of influence that WUCorg, Supp\&Com, and PayPerception have on each other.

Third, important conditions previously identified in the literature as potential factors impacting payment collection were not included in the fsQCA due to negligible variance between cases or lack of information in each case to assess the presence or absence of a specific condition. Moreover, there may be other unobserved sources that explain why users are able to pay for water revenues more promptly or that influence the community's decision to adopt a particular payment collection approach, that were not captured in this study.

Finally, while this study focused on PM services under a PPP framework, additional research could expand upon analysis and results by comparing and contrasting different O\&M approaches and payment collection frameworks. Indeed, analyzing and comparing how different payment structures influence the conditions present within communities that motivate or hinder collective payment compliance could better inform future strategy.

\section{Conclusions}

This study sought to investigate the combinations of conditions that influence payment compliance in PM service delivery schemes. Through qualitative analyses of water source reports and interviews with households and WUCs gathered from a new PM program in the Kamuli District of Uganda, we identified and characterized conditions that appeared to contribute to communities that were compliant with, or suspended from, PM service payments. Then, we employed fsQCA to determine the combinations of conditions that led to payment compliance.

The persistent emergence of WUCorg and WatAvail\&Qual conditions in fsQCA pathway solutions, combined with our case knowledge, showed the importance of these conditions for achieving project sustainability. Therefore, alongside providing water perceived to be of good quality that is available in adequate quantities, external partners need to ensure that a strong WUC is present.

While the PM service provider's program has several tactics to increase the chances of having a well-organized WUC, our findings indicate a further need for stronger support programs with clear communication. The perceived lack of training and support among participants points to a gap that needs to be better explored and addressed. This is especially important for any O\&M framework 
for rural water supply that relies on volunteer-based organizations for revenue collection. Moreover, the potential interlinkages between WUCorg, SuppECom, and PayPerception identified in the study reinforce the need to build capacity among WUCs around subjects such as payment perception, communication strategies, and conflict resolution skills. Not only is there a need to build capacity around these skills, but the analysis also highlights the opportunity to address these other conditions through stronger support and training programs.

Based on participants' perceived lack of training, we believe that there is opportunity to improve the existing PM service provider's program by applying approaches to increase learning, behavior change, and program outcomes arising from investments in training. To help maintain positive management and governance practices within the WUC, it is important to introduce or encourage practices that mitigate potential conflicts within the WUC. It is also important to guide communities through the decision of which payment structure fits best to their context, as well as to introduce or encourage practices that minimize the challenges of payment collection.

While our findings indicate that a strong WUC with proper support and training can improve the likelihood of project success, it cannot solely account for payment compliance. For example, existence of nearby improved water sources poses a significant challenge to water revenues collection, which, in turn, calls for coordinated planning of rehabilitations and locations of new water sources. Interestingly, our findings also indicate that users, depending on their previous experiences with O\&M of water sources, value reliable and fast maintenance service over nearby improved water sources with intermittent functionality. The importance of this condition reflects a community's willingness to pay for reliable services as a way of overcoming the mistrust that stems from the misuse of funds and poor $\mathrm{O} \& \mathrm{M}$ of their water system. Another interesting finding was the potential interchangeability between BreakDown and AltSources - where the existence of the former supersedes the latter, and vice versa.

In general, these insights into important condition combinations may be helpful for external partners, as well as for different levels of government, who provide support to communities with water revenue collection. As future trends in rural water point management appear to be growing towards private external support structures, and away from traditional CBM schemes, this study shows that the challenge of mobilizing resources for O\&M is not solely a problem of the CBM institutional approach, but is also important in a PPP context. Our findings indicate that an active and organized WUC continues to be critical to program success.

Supplementary Materials: The following are available online at http://www.mdpi.com/2071-1050/11/13/3726/s1, Table S1. Causal Conditions, Table S2. Survey instrument, Table S3. Calibration scores and definitions for conditions and outcomes, and Table S4. Truth Table.

Author Contributions: L.O. led the research conceptualization, data collection, and curation. L.O., J.W., A.J.-W., and K.L. shared methodology, project administration, formal analysis, and creation of visualizations, and the structure of the original manuscript draft. Funding was provided by the Sustainable WASH Systems Learning Partnership indicated below, awarded to PI K.L. and Co-PI A.J.-W. All authors were instrumental in manuscript editing and review.

Funding: This material is based in part upon work supported by the Sustainable WASH Systems Learning Partnership (grant \# AID-OAA-A-16-00075), a global U.S. Agency for International Development cooperative agreement led by the University of Colorado Boulder. Any opinion, findings, and conclusions or recommendations expressed in this material are those of the author and do not necessarily reflect the views of partner organizations or the U.S. Government.

Acknowledgments: The authors gratefully acknowledge study participants for access to documentation and important information.

Conflicts of Interest: The authors declare no conflict of interest.

\section{References}

1. Harvey, P.A.; Reed, R.A. Community-managed water supplies in Africa: Sustainable or dispensable? Community Dev. J. 2007, 42, 365-378. [CrossRef] 
2. Arlosoroff, S.; Tschannerl, G.; Grey, D.; Journey, W.; Karp, A.; Langenegger, O.; Roche, R. Community Water Supply: The Handpump Option; The World Bank: Washington, DC, USA, 1987.

3. Briscoe, J.; De Ferranti, D.M. Water for Rural Communities: Helping People to Help Themselves; World Bank: Washington, DC, USA, 1988; ISBN 978-0-8213-0964-3.

4. Moriarty, P.; Smits, S.; Butterworth, J.; Franceys, R. Trends in Rural Water Supply: Towards a Service Delivery Approach. Water Altern. 2013, 6, 329-349.

5. Parry-Jones, S. Optimising the Selection of Demand Assessment Techniques for Water Supply and Sanitation Projects; Project task; Water and Environmental Health at London and Loughborough (WELL): London, UK, 1999.

6. Hope, R.; Rouse, M. Risks and responses to universal drinking water security. Philos. Trans. R. Soc. A Math. Phys. Eng. Sci. 2013, 371, 20120417. [CrossRef] [PubMed]

7. Therkildsen, O. Watering White Elephants? Lessons from Donor Funded Planning and Implementation of Rural Water Supplies in Tanzania; Scandinavian Institute of African Studies: Uppsala, Sweden, 1988.

8. Thompson, J.; Porras, L.; Tumwine, J.; Mujwahuzi, M.; Katui-Katua, M.; Johnstone, N. Drawers of Water II: 30 Years of Change in Domestic Water Use and Environmental Health in East Africa; International Institute for Environment and Development: London, UK, 2001.

9. Gasparro, K.E.; Walters, J.P. Revealing causal pathways to sustainable water service delivery using fsQCA. J. Water Sanit. Hyg. Dev. 2017, 7, 546-556. [CrossRef]

10. Foster, T.; Furey, S.; Banks, B.; Willetts, J. Functionality of handpump water supplies: A review of data from sub-Saharan Africa and the Asia-Pacific region. Int. J. Water Resour. Dev. 2019, 28. [CrossRef]

11. Foster, T. Predictors of Sustainability for Community-Managed Handpumps in Sub-Saharan Africa: Evidence from Liberia, Sierra Leone, and Uganda. Environ. Sci. Technol. 2013, 47, 12037-12046. [CrossRef] [PubMed]

12. Van den Broek, M.; Brown, J. Blueprint for breakdown? Community Based Management of rural groundwater in Uganda. Geoforum 2015, 67, 51-63. [CrossRef]

13. MWE. A National Framework for Operation and Maintenance of Water Supplies; Ministry of Water and Environment, Republic of Uganda: Kampala, Uganda, 2004.

14. Carter, R.C.; Tyrrel, S.F.; Howsam, P. The impact and sustainability of community water supply and sanitation programmes in developing countries. Water Environ. J. 1999, 13, 292-296. [CrossRef]

15. Hutchings, P.; Chan, M.Y.; Cuadrado, L.; Ezbakhe, F.; Mesa, B.; Tamekawa, C.; Franceys, R. A systematic review of success factors in the community management of rural water supplies over the past 30 years. Water Policy 2015, 17, 963-983. [CrossRef]

16. Klug, T.; Shields, K.F.; Cronk, R.; Kelly, E.; Behnke, N.; Lee, K.; Bartram, J. Water system hardware and management rehabilitation: Qualitative evidence from Ghana, Kenya, and Zambia. Int. J. Hyg. Environ. Health 2017, 220, 531-538. [CrossRef]

17. Whittington, D.; Davis, J.; Prokopy, L.; Komives, K.; Thorsten, R.; Lukacs, H.; Bakalian, A.; Wakeman, W. How well is the demand-driven, community management model for rural water supply systems doing? Evidence from Bolivia, Peru and Ghana. Water Policy 2009, 11, 696. [CrossRef]

18. Carter, R.C.; Harvey, E.; Casey, V. User financing of rural handpump water services. In Proceedings of the IRC Symposium 2010: Pumps, Pipes and Promises, Hague, The Netherlands, 16-18 November 2010.

19. Chowns, E. Is Community Management an Efficient and Effective Model of Public Service Delivery? Lessons from the Rural Water Supply Sector in Malawi: Is Community Management Efficient and Effective? Public Adm. Dev. 2015, 35, 263-276. [CrossRef]

20. Lockwood, H.; Smits, S. Supporting Rural Water Supply: Moving Towards a Service Delivery Approach; Practical Action Publishing: Warwickshire, UK, 2011; ISBN 978-1-85339-729-5.

21. Lockwood, H. Issue \#6-WaSH Policy Research Digest: Community Management; The Water Institute at UNC: Chapel Hill, NC, USA, 2017.

22. Kleemeier, E.L.; Lockwood, H. Public-Private Partnerships for Rural Water Services; IRC: The Hague, The Netherlands, 2012.

23. Foster, T.; Hope, R. Evaluating waterpoint sustainability and access implications of revenue collection approaches in rural Kenya: Waterpoint sustainability and use in Kenya. Water Resour. Res. 2017, 53, 1473-1490. [CrossRef]

24. Amadei, B. A Systems Approach to Modeling Community Development Projects; Momentum Press LLC: New York, NY, USA, 2016. 
25. Walters, J.P.; Javernick-Will, A.N. Long-Term Functionality of Rural Water Services in Developing Countries: A System Dynamics Approach to Understanding the Dynamic Interaction of Factors. Environ. Sci. Technol. 2015, 49, 5035-5043. [CrossRef] [PubMed]

26. Galli, G.; Nothomb, C.; Baetings, E. Towards Systemic Change in Urban Sanitation; IRC: The Hague, The Netherlands, 2014.

27. Cronk, R.; Bartram, J. Factors Influencing Water System Functionality in Nigeria and Tanzania: A Regression and Bayesian Network Analysis. Environ. Sci. Technol. 2017, 51, 11336-11345. [CrossRef] [PubMed]

28. Chatterley, C.; Linden, K.G.; Javernick-Will, A. Identifying pathways to continued maintenance of school sanitation in Belize. J. Water Sanit. Hyg. Dev. 2013, 3, 411-422. [CrossRef]

29. Chatterley, C.; Javernick-Will, A.; Linden, K.G.; Alam, K.; Bottinelli, L.; Venkatesh, M. A qualitative comparative analysis of well-managed school sanitation in Bangladesh. BMC Public Health 2014, 14, 6. [CrossRef]

30. Kaminsky, J.; Javernick-Will, A. Contested Factors for Sustainability: Construction and Management of Household On-Site Wastewater Treatment Systems. J. Constr. Eng. Manag. 2013, 139, A4013004. [CrossRef]

31. Spang, E.S.; Moomaw, W.R.; Gallagher, K.S.; Kirshen, P.H.; Marks, D.H. The water consumption of energy production: An international comparison. Environ. Res. Lett. 2014, 9, 105002. [CrossRef]

32. Marks, S.J.; Kumpel, E.; Guo, J.; Bartram, J.; Davis, J. Pathways to sustainability: A fuzzy-set qualitative comparative analysis of rural water supply programs. J. Clean. Prod. 2018, 205, 789-798. [CrossRef]

33. Kaminsky, J.; Javernick-Will, A. The Internal Social Sustainability of Sanitation Infrastructure. Environ. Sci. Technol. 2014, 48, 10028-10035. [CrossRef] [PubMed]

34. Ragin, C.C. Redesigning Social Inquiry: Fuzzy Sets and Beyond; University of Chicago Press: Chicago, IL, USA, 2008; ISBN 978-0-226-70273-5.

35. Ragin, C.C.; Shulman, D.; Weinberg, A.; Gran, B. Complexity, Generality, and Qualitative Comparative Analysis. Field Methods 2003, 15, 323-340. [CrossRef]

36. Opdyke, A.; Javernick-Will, A.; Koschmann, M. A Comparative Analysis of Coordination, Participation, and Training in Post-Disaster Shelter Projects. Sustainability 2018, 10, 4241. [CrossRef]

37. Ragin, C.C. The Comparative Method: Moving beyond Qualitative and Quantitative Strategies; University of California Press: Berkeley, CA, USA, 1987; ISBN 978-0-520-06618-2.

38. Rihoux, B. Qualitative Comparative Analysis (QCA), Anno 2013: Reframing The Comparative Method's Seminal Statements. Swiss Political Sci. Rev. 2013, 19, 233-245. [CrossRef]

39. Thomann, E.; Maggetti, M. Designing Research with Qualitative Comparative Analysis (QCA): Approaches, Challenges, and Tools. Sociol. Methods Res. 2017, 1-31. [CrossRef]

40. Vink, M.P.; Van Vliet, O. Not Quite Crisp, Not Yet Fuzzy? Assessing the Potentials and Pitfalls of Multi-value QCA. Field Methods 2009, 21, 265-289. [CrossRef]

41. Vink, M.P.; Vliet, O. van Potentials and Pitfalls of Multi-value QCA: Response to Thiem. Field Methods 2013, 25, 208-213. [CrossRef]

42. Kaminsky, J.; Jordan, E. Qualitative comparative analysis for WASH research and practice. J. Water Sanit. Hyg. Dev. 2017, 7, 196-208. [CrossRef]

43. MWE. Water and Environment Sector Performance Report 2014; Ministry of Water and Environment: Luzira, Uganda, 2014.

44. Whave Personal Correspondance: Preventative Maintenance Agreement Data. 2017.

45. Quin, A.; Balfors, B.; Kjellén, M. How to "walk the talk": The perspectives of sector staff on implementation of the rural water supply programme in Uganda: How to "walk the talk". Nat. Resour. Forum 2011, 35, 269-282. [CrossRef]

46. Terry, A.; McLaughlin, O.; Kazooba, F. Improving the effectiveness of Ugandan water user committees. Dev. Pract. 2015, 25, 715-727. [CrossRef]

47. Foster, T.; Hope, R. A multi-decadal and social-ecological systems analysis of community waterpoint payment behaviours in rural Kenya. J. R. Stud. 2016, 47, 85-96. [CrossRef]

48. Parry-Jones, S.; Reed, R.; Skinner, B.H. Sustainable Handpump Projects in Africa: A Literature Review; Water, Engineering and Development Centre: Loughborough, UK, 2001.

49. Koehler, J.; Thomson, P.; Hope, R. Pump-Priming Payments for Sustainable Water Services in Rural Africa. World Dev. 2015, 74, 397-411. [CrossRef] 
50. Richards, L. Handling Qualitative Data: A Practical Guide, Sage Publications: London, UK, 2005; ISBN 0-7619-4259-9.

51. Maxwell, J.A. Qualitative Research Design: An Interactive Approach, 3rd ed.; Applied Social Social Research Methods (Book 41); SAGE Publications Inc.: Thousand Oaks, CA, USA, 2013; ISBN 978-1-4129-8119-4.

52. Saldaña, J. The Coding Manual for Qualitative Researchers; SAGE Publications Inc.: Thousand Oaks, CA, USA, 2009; ISBN 978-1-4462-4737-2.

53. Jordan, E.; Gross, M.; Javernick-Will, A.; Garvin, M. Use and misuse of qualitative comparative analysis. Constr. Manag. Econ. 2011, 29, 1159-1173. [CrossRef]

54. Ragin, C.C. Fuzzy-set/Qualitative Comparative Analysis; University of Arizona: Tuscon, AZ, USA, 2013.

55. Rihoux, B.; Ragin, C.C. Configurational Comparative Methods: Qualitative Comparative Analysis (QCA) and Related Techniques; SAGE Publications, Inc.: Thousand Oaks, CA, USA, 2009.

56. Kamruzzaman, A.K.M.; Said, I.; Osman, O. Overview on Management Patterns in Community, Private and Hybrid Management in Rural Water Supply. J. Sustain. Dev. 2013, 6, 26-36. [CrossRef]

57. Kativhu, T.; Mazvimavi, D.; Tevera, D.; Nhapi, I. Factors influencing sustainability of communally-managed water facilities in rural areas of Zimbabwe. Phys. Chem. Earth Parts A/B/C 2017, 100, 247-257. [CrossRef]

(C) 2019 by the authors. Licensee MDPI, Basel, Switzerland. This article is an open access article distributed under the terms and conditions of the Creative Commons Attribution (CC BY) license (http://creativecommons.org/licenses/by/4.0/). 